\title{
Exclusive breastfeeding practice and associated factors among mothers in Motta town, East Gojjam zone, Amhara Regional State, Ethiopia, 2015: a cross-sectional study
}

Tilahun Tewabe ${ }^{1 *}$, Alemnesh Mandesh², Tenaw Gualu³, Girma Alem³ ${ }^{3}$ Getnet Mekuria ${ }^{3}$ and Haymanot Zeleke ${ }^{3}$

\begin{abstract}
Background: Exclusive breastfeeding means babies are given only breast milk and nothing else: no other milk, food, drink, not even water for one day (24 hrs) before the survey was conducted. It prevents $13 \%$ of childhood mortality; i.e, at least 1.2 million children worldwide would be saved every year. The objective of this study was to assess the prevalence exclusive breastfeeding (EBF) practice and its associated factor among mothers who have infants less than six months of age in Motta town, East Gojjam, Amhara Regional State, Ethiopia.
\end{abstract}

Method: A community based quantitative cross-sectional study was conducted from April 7, 2015 to May 7, 2015. A simple random sampling technique was applied after taking all registered mothers who have infants less than six months old from local health extension workers of each kebele. A total of 423 mothers with infant less than six months old were included in this study.

The data was collected using an interviewer administered questioaire. Both bivariate and multivariate logistic regression analyses were used to identify factors associated with exclusive breastfeeding practice.

Result: Prevalence of exclusive breastfeeding was $50.1 \%$. Mothers with young infants aged 0-1 month (Adjusted Odds Ratio [AOR] 3.86: (1.64, 9.07), unemployed mothers (AOR 3.01: 1.46, 6.20), low income mothers (AOR 3.61: 1.75, 7.45), mothers who received breastfeeding counseling in pregnancy (AOR 2.76: 1.52, 4.99), fed colostrum (AOR 3.50: 1.45, 8. 45), didn't give prelacteal feeds (AOR 4.48: 1.82, 11.03) and were supported by their husband (AOR 2.67: 1.04, 6.95) were more likely to practice exclusive breastfeeding than their counterparts.

Conclusions: Prevalence of exclusive breastfeeding practice in study area was lower than country recommended level. Age of the child, maternal occupation, income, breastfeeding counseling during antenatal care, husband support of breastfeeding and colostrum feeding were independent predictors of exclusive breastfeeding practice. Recommendations to increase exclusive breastfeeding practice are revising postpartum maternity leave, increasing health professional's habit of breastfeeding counseling through training, involving husbands during counseling, educating mothers and the community as a whole to avoid traditional practices that hinder exclusive breastfeeding up to six months.

Keywords: Exclusive breastfeeding, Prevalence, Motta, Ethiopia

\footnotetext{
* Correspondence: bezatewabe01@gmail.com

'Bahir Dar University, College of Medicine and Health science, Bahir Dar,

Ethiopia

Full list of author information is available at the end of the article
} 


\section{Background}

Exclusive breastfeeding provides all infants nutritional and fluid needs in the first six months and is a perfect combination of proteins, fats, carbohydrates and fluids [1]. Exclusively breastfeed children are at a much lower risk of infections [2-4] and it is the best and cost effective intervention to reduce infant morbidities and mortalities [1].

Over two-thirds deaths occurring world wide during the first year of life children are often associated with inappropriate feeding practices, especially due to poor exclusive breastfeeding practices [5]. Suboptimal breastfeeding contributes to $45 \%$ of neonatal infectious deaths, $30 \%$ of diarrheal deaths and $18 \%$ of acute respiratory deaths among under five years of age children in developing countries [6]. It also accounts on $10 \%$ of the disease burden in children less than 5 years old [7].

A total of $96 \%$ of all infant deaths i.e. 1.24 million deaths occur during the first six months of life are attributable to non exclusive breastfeeding which is much higher in Asia and Africa. It accounts 55\% of diarrheal deaths and $53 \%$ of acute respiratory deaths in the first six months of life [8]. Compared with exclusive breastfeeding in the first few months of life, partial or no breastfeeding is associated with a 2.23-fold higher risk of infant deaths resulting from all causes and 2.40 and 3.94 fold higher risk of deaths attributable to pneumonia and diarrhea, respectively [9].

Non exclusive breastfeeding is known to compromise the nutritional status of children. It results an estimated $40 \%$ of under-five stunting in Western and Central Africa (WCA) and more than 60\% in some other countries [10].

Exclusive breastfeeding from birth to six months has the potential to prevent $13 \%$ of child mortality [2]. However, no more than $35 \%$ of infants worldwide are exclusively breastfeeding during the first four months of life [10]. Only $38 \%$ of children less than six months of age are exclusively breastfed in the developing countries [11] and $21 \%$ in WCA [10].

In Ethiopia suboptimal breastfeeding practices are the major contributor to an estimated 70,000 infant deaths per year, $24 \%$ of the total infant death annually and which can be significantly prevented by nutrition interventions such as exclusive breastfeeding [11].

In Ethiopia, $52 \%$ of children less than six months old are exclusively breastfed [12]. The Ethiopian Health Sector Development Program (HSDP) IV planned to increase in the proportion of exclusively breastfeeding infants under the age of six months to $70 \%$ by the end of 2015 [13].

Breastfeeding and good nutrition for children are recognized as essential for achieving the Millennium Development Goals (MDG), particularly the goals relating to child survival, such as reducing child mortality by $2 / 3$ between 1990 and 2015 [5, 8].
Therefore the purpose of this study was to assess exclusive breastfeeding practices and the associated factors among mothers of children less than six months old in Mottatown, East Gojjam zone, Ethiopia.

\section{Methods}

Study setting and participants

A community based quantitative cross-sectional study was conducted from April 7 to May 7, 2015.

The study was conducted in Motta town which is located in the Amhara National Regional State, East Gojjam Zone, Ethiopia. It is bordered on all sides by Hulet Ejju Enesse woreda. It is $371 \mathrm{kms}$ away from Addis Ababa. Motta town was founded in 1754 . The town has a total of 4 kebeles. The population of the town is 33,500, of which 520 were children less than six months of age. The town has a total of 17 governmental and non governmental health care institutions on work. These are one hospital, one health center, five clinics, one pharmacy and nine drug stores.

The sample size was calculated using single population proportion formula by considering the following assumptions; $p=49.1 \%$ proportion of exclusive breastfeeding practice which was the prevalence of exclusive breastfeeding in Bahir Dar town, North West Ethiopia [14]. Level of confidence $95 \%$, margin of error $(d)=5 \%$ and $10 \%$ non- response rate. Using a simple random sampling technique 423 mothers participated in the study. To select study participants from each kebele, first the sample size was proportionally allocated to size and finally a lottery method was used to select each study participant. Actual age of the infants was determined by asking the mothers and reviewing the birth date certificate.

\section{Measurement}

A structured interviewer administered questionnaire was used to collect data from participants or mothers of a child. It was constructed by adopting from Ethiopia Demographic and Health Survey (EDHS) 2011 [12] and from previous research done on a similar topic $[14,15]$ and modified accordingly. A one day (24 hour) infant diet recall method was used for assessing exclusive breastfeeding. Four diploma nurses were recruited as data collectors and two Bachelor of Science nurses were recruited as supervisors. All data collectors and supervisors were oriented and trained on how to interview and record the data for one day before the start of the survey.

\section{Operational definitions}

Exclusive breastfeeding: If an infant was fed only breast milk (with the exception ordered medicines and vitamins by health professionals) one day ( $24 \mathrm{hrs}$ ) before the survey was conducted [12]. 
Predominant breastfeeding: if an infant mainly took breast milk with non-milk liquid foods such as plain water, tea, salt/sugar solution and juices one day (24 hrs) before the survey was conducted [16].

Mixed breastfeeding: if an infant was fed breast milk with addition of liquid foods like cow milk and formula milk and soft foods like mashed potatoes/meat, porridge, egg, butter one day ( $24 \mathrm{hrs}$ ) before the survey was conducted [16].

Exclusive replacement feeding: If an infant was fed other foods without breast milk one day ( $24 \mathrm{hrs}$ ) before the survey was conducted [12].

\section{Statistical analysis}

The collected data was checked manually for completeness and consistencies, and then it was coded and entered in EPI Info version 3.5.3 and exported to SPSS version 16 for analysis. Descriptive statistics was used to summarize the socio-demographic characteristics' of the study participants and the prevalence of exclusive breastfeeding.To identify factors associated with exclusive breastfeeding practice, binary logistic regression analysis was carried out at two levels, first bivariate logistic regression was performed to each independent variable with the outcome variable and those variables with a $p$ value $<0.05$ were included in the final model (multivariate analysis). The strength of association was measured using odds ratio, and $95 \%$ confidence intervals. Statistical significance was declared at a $p$ value $<0.05$.

\section{Results}

\section{Sociodemographic characteristics}

Out of 423 eligible mothers, 405 were participated in this study, which made a response rate of $95.7 \%$. More than half $(58.8 \%)$ of mothers were below 30 years of age. Most (95.6\%) of mothers were Amhara by ethnicity. With regard to educational status, $242(59.8 \%)$ mothers were educated. Around one fifth (20.4\%) of study participants were employed mothers. The average household income of the respondents was 1524.26 Ethiopian Birr per month (standard deviation [SD] \pm 1259.65 ), and 207 (51.1\%) respondents earn above 1000 Ethiopian Birr per month (Table 1).

\section{Infant and maternal health service utilization characteristics}

Almost one third (27.4\%) children were first in birth order. More than half 231 (57.0\%) of infants were between $120-180$ days old. A majority (86.2\%) of the mothers had an antenatal visit during their pregnancy and 206 (59.0\%) were counseled concerning breastfeeding. Mothers who received postnatal care 186 (94.4\%) were told about exclusive breastfeeding up to six months of age (Table 2).
Table 1 Socio-demographic characteristics mothers (respondents) who have infants less than six months old, in Motta town, East Gojjam Zone, Ethiopia, 2015

\begin{tabular}{llll}
\hline Variable & Category $(n=405)$ & Frequency & Percent (\%) \\
\hline Age of mother & $15-24$ & 111 & 27.4 \\
(in years) & $25-29$ & 127 & 31.4 \\
& 30 and above & 167 & 41.2 \\
Religion & Orthodox & 229 & 56.5 \\
& Others ${ }^{\mathrm{a}}$ & 176 & 43.4 \\
Ethnicity & Amhara & 388 & 95.8 \\
& Others & \\
Level of education & Unducated & 17 & 4.2 \\
of mother & Educated & 242 & 40.2 \\
Occupational status & Employed & 82 & 59.8 \\
of mother & Unemployed & 323 & 79.6 \\
Current marital status & Married & 347 & 85.7 \\
& Unmarried & 58 & 14.3 \\
Husband educational & Unducated & 262 & 59.5 \\
level & Educated & 143 & 40.5 \\
Husband occupation & Employed & 111 & 31.5 \\
& Unemployed & 294 & 68.5 \\
Type of family & Nuclear family & 328 & 80 \\
Household income & Extended family & 77 & 20 \\
(Ethiopain birr) & - 1000 & 198 & 48.9 \\
& 1001-2000 & 107 & 26.4 \\
\hline M2001 & 100 & 24.7 \\
\hline
\end{tabular}

${ }^{a}$ Muslim, Protestant and Catholic

${ }^{\mathrm{b}}$ Oromo, Tigrie and Gurage

csingle, widowed and separated

\section{Exclusive breastfeeding practices}

The prevalence of exclusive breastfeeding practice one day before the survey was $50.1 \%$ (95\% CI: 45.22, $54.98 \%)$. Among mothers who didn't exclusively breastfeed their infant, the main reasons mentioned were; perception of breast milk only being not sufficient for the infant $61(30.2 \%)$, lack of time $46(22.8 \%)$, and decreased breast milk secretion 38 (18.8\%) (Table 3).

The majority (87.8\%) of mothers were supported by their husband to feed their infant exclusively on breast milk. Among employed mothers only 4 (3.7\%) were encouraged by their organization/employer to breastfed their infant (Table 4).

\section{Factors associated with exclusive breastfeeding}

First variables were tested using bivariate analysis. Variables which were associated $(p<0.05)$ in the bivariate analysis were tested in the final multivariate analysis to see their significant association with exclusive breastfeeding practice. 
Table 2 Infant and maternal health service utilization characteristics of study participants in Motta town, East Gojjam zone, Ethiopia, 2015

\begin{tabular}{|c|c|c|c|}
\hline Variable & Response $(n=423)$ & Frequency & $\begin{array}{l}\text { Percent } \\
(\%)\end{array}$ \\
\hline \multirow[t]{2}{*}{ Sex of infant } & Male & 180 & 44.4 \\
\hline & Female & 225 & 55.6 \\
\hline \multirow[t]{3}{*}{ Age of infant } & 0-60 days & 55 & 13.6 \\
\hline & $61-120$ days & 119 & 29.4 \\
\hline & 121-180 days & 231 & 57.0 \\
\hline \multirow[t]{2}{*}{ Birth order } & First & 110 & 27.2 \\
\hline & Second and above & 294 & 73.8 \\
\hline \multirow[t]{2}{*}{ Birth interval } & Up to three years & 236 & 58.3 \\
\hline & $\begin{array}{l}\text { Three years and } \\
\text { above }\end{array}$ & 169 & 41.7 \\
\hline $\begin{array}{l}\text { Antenatal care } \\
(n=405)\end{array}$ & Yes & 349 & 86.2 \\
\hline $\begin{array}{l}\text { Counseling related } \\
\text { breastfeeding during } \\
\text { antenatal follow up } \\
(n=349)\end{array}$ & Yes & 206 & 59.0 \\
\hline \multirow[t]{2}{*}{ Place of birth } & Health facility & 338 & 83.5 \\
\hline & Home & 67 & 16.5 \\
\hline \multirow[t]{2}{*}{ Mode of delivery } & Vaginal /normal & 367 & 90.6 \\
\hline & Caeserian section & 38 & 9.4 \\
\hline Postnatal care $(n=405)$ & Yes & 197 & 48.6 \\
\hline $\begin{array}{l}\text { Counseling regarding to } \\
\text { breastfeeding during } \\
\text { postnatal care }(n=197)\end{array}$ & Yes & 186 & 94.4 \\
\hline
\end{tabular}

The independent predictors of exclusive breastfeeding were; age of infant, occupation of mother, marital status, income of the household, antenatal care, breastfeeding counseling during antenatal care, place of birth, mode of delivery, postnatal care, timely initiation of breastfeeding, colostrum feeding, prelacteal feeding and husbands support.

The final predictors for exlusive breastfeeding practice were; age of infant, maternal occupation, household income, breastfeeding counseling during antenatal care, husband's support of breastfeeding, colostrum feeding and prelacteal feeding.

An infant who is $0-1$ month old was four times more likely to exclusively breastfed than infant aged 4-5 months (AOR 3.86: 1.64, 9.07). Similarly infants aged 2-3 months were almost two times more likely to feed exclusively on breast milk than 4-5 month old infants (AOR 2.24: 1.16, 4.31).

Concerning to occupation, unemployed mothers were three times more likely to practice EBF than employed mothers (AOR 3.01: 1.46, 6.20). Income was significantly associated with EBF practice. Mothers who earn less money ( $\leq 1000$ Ethiopian birr/month) were 3.6 times
Table 3 Breastfeeding related practices of mothers who have infants less than six months old in Motta town, East Gojjam zone, Ethiopia, 2015

\begin{tabular}{|c|c|c|c|}
\hline Variables & Responses $(n=405)$ & Frequency & $\overline{\text { Percent }}$ \\
\hline $\begin{array}{l}\text { Colostrum feeding } \\
(n=405)\end{array}$ & Yes & 323 & 79.8 \\
\hline \multirow{4}{*}{$\begin{array}{l}\text { Infant feeding practice } \\
\text { one day before the } \\
\text { survey }\end{array}$} & Exclusively breastfeeding & 203 & 50.1 \\
\hline & $\begin{array}{l}\text { Predominantly } \\
\text { breastfeeding }\end{array}$ & 156 & 38.5 \\
\hline & Mixed breastfeeding & 46 & 9.9 \\
\hline & $\begin{array}{l}\text { Exclusive replacement } \\
\text { feeding }\end{array}$ & 6 & 1.5 \\
\hline \multirow{6}{*}{$\begin{array}{l}\text { Reasons for not } \\
\text { exclusively } \\
\text { breastfed }(n=202)\end{array}$} & $\begin{array}{l}\text { Decreased breast milk } \\
\text { secretion }\end{array}$ & 38 & 18.8 \\
\hline & $\begin{array}{l}\text { Breast milk only not } \\
\text { sufficient for infant }\end{array}$ & 61 & 30.2 \\
\hline & Infant becomes thirsty & 25 & 12.4 \\
\hline & Lack of time & 46 & 22.8 \\
\hline & Maternal illness & 26 & 12.9 \\
\hline & Breast problem & 6 & 3.0 \\
\hline \multirow{5}{*}{$\begin{array}{l}\text { Who influenced you to } \\
\text { give other feeding } \\
(n=202)\end{array}$} & Husband/spouse & 39 & 19.3 \\
\hline & My mother & 23 & 11.4 \\
\hline & Mother in law & 3 & 1.5 \\
\hline & Health worker & 6 & 3.0 \\
\hline & My own decision & 131 & 64.8 \\
\hline
\end{tabular}

more likely to practice exclusive breastfeeding than mothers whose average monthly household income was 2001 Ethiopian birr and above (AOR 3.61: 1.75, 7.45). While mothers who earn between 1001- 2000 Ethiopian birr/month were almost two times more likely to practice EBF than those who earn $\geq 2001$ Ethiopian birr/ month (AOR 2.34: 1.12, 4.91).

Mothers who were counseled regarding to breastfeeding during antenatal care were almost three times more likely to practice exclusive breastfeeding than mothers who were not counseled (AOR 2.76: 1.52, 4.99).

Mothers who fed colostrum to their infant were 3.5 times higher to practice EBF than those who didn't feed colostrum (AOR 3.50: 1.45, 8.45). On the other hand, mothers who didn't give prelacteal food to their infant were almost four times more likely to practice EBF than mothers who fed prelacteal food (AOR 4.48: 1.82, 11.03).

Pertaining to support, mothers who had their husband's support for breastfeeding were almost three times more likely to practice EBF than mothers who were not supported by their husband (AOR 2.686: 1.037, 6.953) (Table 5).

\section{Discussion}

In spite of what is known about the benefit of exclusive breastfeeding; the practice is not satisfactory in the study 
Table 4 Type of support systemand source of information of mothers about exclusive breastfeeding among those who have an infant less than six monthold in Motta town, East Gojjam zone, Ethiopia, 2015

\begin{tabular}{lllc}
\hline Variables & Responses & Frequecy & Percent (\%) \\
\hline Husband support $(n=353)$ & Yes & 310 & 87.8 \\
Religious father support $(n=405)$ & Yes & 20 & 4.9 \\
Organizational support of EBF $(n=82)$ & Yes & 4 & 3.7 \\
Cultural support of EBF $(n=405)$ & Yes & 34 & 0.5 \\
Source of information about exclusive breastfeeding & Radio & 3.4 & 48.1 \\
& Television & 307 & 84.8 \\
& Health extension workers & 240 & 32 \\
\hline
\end{tabular}

Table 5 Factors that affect EBF practice among mothers of infants age less than 6 months using bivariate and multivariate logistic regression analysis model, East Gojjam, Ethiopia, 2015

\begin{tabular}{|c|c|c|c|c|c|}
\hline \multirow[t]{2}{*}{ Variables } & \multicolumn{5}{|l|}{ EBF Practice } \\
\hline & & $\begin{array}{l}\text { Yes } \\
(n \& \%)\end{array}$ & $\begin{array}{l}\text { No } \\
(n \& \%)\end{array}$ & COR $(95 \% \mathrm{CL})$ & AOR (95\% CL) \\
\hline \multirow[t]{3}{*}{ Age of child in months } & $0-1$ & $37(67.3)$ & $18(32.7)$ & $2.84(1.53,5.28)$ & $3.86(1.64,9.07)^{*}$ \\
\hline & $2-3$ & $69(58.0)$ & $50(42.0)$ & $1.91(1.22,2.98)$ & $2.24(1.16,4.31)^{*}$ \\
\hline & $4-5$ & $97(42.0)$ & $134(58.0)$ & 1 & 1 \\
\hline \multirow{2}{*}{$\begin{array}{l}\text { Occupational } \\
\text { status }\end{array}$} & Unemployed & $173(53.6)$ & $150(46.4)$ & $1.99(1.21,3.30)$ & $3.01(1.46,6.20)^{*}$ \\
\hline & Employed & $30(36.6)$ & $52(63.4)$ & 1 & 1 \\
\hline \multirow[t]{2}{*}{ Marital status } & Married & $182(52.4)$ & $165(47.6)$ & $1.94(1.10,3.46)$ & \\
\hline & Unmarried & $21(36.2)$ & 37 (63.6) & 1 & \\
\hline \multirow[t]{3}{*}{ Income } & $\leq 1000$ & $114(57.6)$ & $84(42.4)$ & $2.63(1.59,4.35)$ & $3.61(1.75,7.45)^{*}$ \\
\hline & $1001-2000$ & $55(51.4)$ & $52(48.6)$ & $2.05(1.17,3.59)$ & $2.34(1.12,4.92)^{*}$ \\
\hline & $\geq 2001$ & $34(34.0)$ & $66(66.0)$ & 1 & 1 \\
\hline \multirow[t]{2}{*}{ Antenatal care } & Yes & $185(53)$ & $164(47)$ & $2.38(1.31,4.34)$ & \\
\hline & No & $18(32.1)$ & $38(67.9)$ & 1 & \\
\hline \multirow{2}{*}{$\begin{array}{l}\text { Breastfeeding counseling } \\
\text { during antenatal care }\end{array}$} & Yes & $131(63.6)$ & 75 (36.4) & $2.88(1.85,4.48)$ & $2.76(1.52,4.99)^{*}$ \\
\hline & No & $54(37.8)$ & $89(62.2)$ & 1 & 1 \\
\hline \multirow[t]{2}{*}{ Place of birth } & Health facility & $185(54.7)$ & $153(45.3)$ & $3.29(1.84,5.89)$ & \\
\hline & Home & $18(26.9)$ & $49(73.1)$ & 1 & \\
\hline \multirow[t]{2}{*}{ Mode of delivery } & Normal/vaginal & $190(51.8)$ & $177(48.2)$ & $2.06(1.02,4.16)$ & \\
\hline & Ceaserian section & $13(34.2)$ & $25(65.8)$ & 1 & \\
\hline \multirow[t]{2}{*}{ Postnatal care } & Yes & $116(58.9)$ & $81(41.1)$ & $1.99(1.34,2.96)$ & \\
\hline & No & $87(41.8)$ & $121(58.2)$ & 1 & \\
\hline \multirow[t]{2}{*}{ Colostrum feeding } & Yes & $185(57.3)$ & $138(42.7)$ & $4.77(2.70,8.41)$ & $3.50(1.45,8.45)^{*}$ \\
\hline & No & $18(22)$ & $64(78)$ & 1 & 1 \\
\hline \multirow[t]{2}{*}{ Prelacteal feeding } & No & $189(58.7)$ & $133(41.3)$ & $6.90(3.73,12.79)$ & $4.48(1.82,11.03)^{*}$ \\
\hline & Yes & $14(17.1)$ & $68(82.9)$ & 1 & 1 \\
\hline \multirow[t]{2}{*}{ Husbands support } & Yes & $174(56.1)$ & $136(43.9)$ & $4.22(2.01,8.87)$ & $2.69(1.04,6.95)^{*}$ \\
\hline & No & $10(23.3)$ & $33(76.7)$ & 1 & 1 \\
\hline
\end{tabular}

$1=$ reference, $\mathrm{gg} *=p$-value less than $0.05, n=$ number $\%=$ percent 
area. Only half, 50.1\% (95\% CI: $45.22 \%$ - 54.98\%) of mothers reported they were exclusively breastfeeding their infant, which is lower than Ethiopian HSDP IV target level of $70 \%$ [13]. This result is comparable to the 2011 EDHS 52\% [12], EDHS 2005 49\% [17] and with other similar studies done in; Bahir Dar, Ethiopia 49.1\% [14], Kumasi Metropolis, Ghana 48\% [18], Mecha district, NorthWest, Ethiopia 47.13\% [19] and Dare Salaam, Tanzania 46\% [20]. This finding is higher than; worldwide prevalence 35\% [5], SSA 31\% [6] and from other studies from; Malaysia 44.3\% [15], Injibara, Awi zone 44\% [21], Ambo 42.3\% [22], Axum 40.9\% [23], Bangladish 36\% [24], Nairobi, Kenya 34\% [25], Egypt 29.9\% [26], Sudan 29.5\% [27] and Nigeria 20\% [28]. However the result is lower than studies from Kigoma, Tanzania 58\% [29] and Debre Markos, Ethiopia 60.8\% [16]. The difference might be due to methodological variations between studies and differences in sociocultural, economical, health and health service utilization characteristics between respondents of the referenced areas and the study place.

In this study unemployed mothers practiced EBF better than employed mothers. This result is similar to studies from: Malaysia [15, 30], the Netherlands [31], Utah State [32], Cameroon [33], Timor-Leste [34], Ghana [18], Awi Zone, Ethiopia [22], and Debre Markos, Ethiopia [16]. On the other hand mothers with better economical status practised EBF poorly. This is in line with research findings in Cape Metropole [35] and Nigeria. This might be because mothers who earn less money have no any option to buy other food and employed mothers tend not to breastfeed their infant exclusively due to: short period of maternity leave, lack of time, distance of the workplace from home, lack private space for breastfeeding or expressing milk at the workplace, inflexible work schedule, absence of on site or near site child care centers.

In this study breastfeeding counseling during preganancy were found to facilitate exclusive breastfeeding practice. This finding is parallel with studies done with low income Latinos in US [36], Nigeria and Debre Markos, Ethiopia [16]. This could be counseling enhances mothers' understanding and appreciation of the demands and benefits of EBF. Mothers who were counseled during pregnancy prepared themselves psychologically as well economically to exclusively breastfeed the infant.

Colostrum feeding facilitates exclusive breastfeeding since it promotes the early initiation of breastfeeding which also increases child survival. This finding is consistent with findings in Axum [23] and Dabat, Gonder [37]. Whereas giving prelacteal feeding hinders the practice of EBF, which is similar with findings in Al Hasa, Saudi Arabia [38] and Debre Markos, Ethiopia [16]. This might be due to the fact that when mothers introduce other food to the newborn before breastfeeding, it decreases the infants suckling activity and which in turn affects or decreases maternal milk secretion.

Husbands support had a significant relationship with EBF practice in the study area. A mother who was supported by their husband's practiced EBF better than those who were not supported. Which is similar with findings in Malaysia [30] and Injibara town, Awi Zone, Ethiopia [21]. This might be because in Ethiopia a husband plays a major role in the decision making about family and household issues and which affects many aspects of family life including infant feeding practices.

A limitation of this study was that it assessed only the quantitative aspects of exclusive breastfeeding and it may have underestimated the prevalence of exclusive breastfeeding in the study area due to recall bias and because strength representativeness was increased, since it was a community based study.

\section{Conclusion}

The prevalence of exclusive breastfeeding in the study area was lower than the country recommended level. Age of the child, maternal occupation, income, breastfeeding counseling during antenatal care, husbands support, colostrum feeding and not giving prelacteal feeds were the determinant factors for higher chance of EBF practice in the study area.

Recommendations for improving EBF include; extending maternal leave, constructing on-site or near site child care centers, behavior change communication to avoid traditional activities training of health professionals regarding to infant feeding practices and higher socio-economic class mothers should be given priority. Every arrangement should be made to increase their exclusive breastfeeding practice, community based breastfeeding education and counseling to pregnant women and husbands should be given.

\section{Abbreviations}

ANC: Antenatal Care; AOR: Adjusted Odds Ratio; Cl: Confidence Interval; EDHS: Ethiopian Demographic Health Survey; SD: Standard Deviation; UNICEF: United Nation Children Emergeny Fund; WHO: World Health Organization

\section{Acknowledgements \\ This study received financial support from Addis Ababa University College of Health Sciences School of Allied Health Sciences. We would like to thank librarian staffs the school for their cooperation during the study. The study participants are duly acknowledged for voluntarily responding to the questionnaire. We are indebted to data collectors and supervisors for their cooperation during the field work.}

\section{Funding}

Not applicable.

\section{Availability of data and materials}

The data of this study can't be shared publically due to presence of sensitive (confidential) participants' information. 


\section{Authors' contribution}

TT contributed to the design of this study. All authors collected, analyzed and interpreted the data; drafted the manuscript for important intellectual content. The authors reviewed and revised the draft further and approved the final version for submission.

\section{Competing interests}

The authors declare that they have no competing interest.

\section{Consent for publication}

Not applicable.

\section{Ethics approval and consent to participate}

Ethical clearance was obtained from Addis Ababa Unversity, department of nursing and midwifery research committee. Each study participant was adequately informed about the objective of the study and the anticipated benefit and risk of the study by their data collector. Respondents were also told of their right not to respond to questions if they did not want to respond or if they wished to terminate the interview at any time.

\section{Author details}

${ }^{1}$ Bahir Dar University, College of Medicine and Health science, Bahir Dar, Ethiopia. ${ }^{2}$ Addis Ababa University College of Health Sciences School of Allied Health Sciences, Addis Ababa, Ethiopia. ${ }^{3}$ DebreMarkos University, College of Medicine and Health science, Bahir Dar, Ethiopia.

Received: 17 June 2016 Accepted: 11 February 2017

Published online: 27 February 2017

\section{References}

1. UNICEF. Tracking progress on Child and Maternal Nutrition:A Survival and Development Priority. New York: UNICEF; 2009.

2. Federal Ministry of Health, Family Health Department of Ethiopia. National Strategy on Infant and Young Child Feeding. Addis Ababa: Federal Ministry of Health, Family Health Department of Ethiopia; 2004.

3. Indian Academy of Pediatrics. Infant and Young Child Feeding Guidelines. Indian Pediatr. $2010 ; 47(12): 995-1004$.

4. Ministry of Human Resource Development Department of Women and Child Development (Food and Nutrition Board) Government of India. National Guide Line of Infant and Young Child Feeding. India. 2004

5. WHO. Exclusive Breastfeeding for Six Months Best for Babies. Geneva: WHO; 2011

6. WHO. Mortality and Burden of Disease Attributable to Selected Major Risks. Geneva: WHO; 2009.

7. WHO. Infant and Young Child Feeding Model Chapter for Textbooks for Medical Students and Allied Health Professionals. Geneva: WHO; 2009.

8. USAID. MCH Program Description, Overall MCH and Health Sector Situation of Ethiopia. Ethiopia: USAID; 2008.

9. Arifeen S, Black RE, Antelman G, Baqui A, Caulfield L, Becker S. Exclusive breastfeeding reduces acute respiratory infection and diarrhea deaths among infants in Dhaka slums. Pediatrics. 2001;108(4):e67.

10. UNICEF. A Successful Start in Life: Improving Breastfeeding in West And Central Africa. New York: UNICEF; 2010.

11. Ethiopian Federal Ministry of Health. National Strategy for Child Survival. Addis Ababa, Ethiopia;2015.

12. Central Statistical Agency. Ethiopia Demographic and Health Survey 2011. Addia Ababa, Ethiopia. Calverton, Maryland: ICF International; 2012.

13. Federal Ministry of Health. Ethiopian Health Sector Development Programme IV:2010/2011-2014/2015. Adddis Ababa: Ethiopian federal minstry of health; 2010.

14. Sefene A, Birhanu D, Awoke W, Taye T. Determinants of exclusive breastfeeding practice among mothers of children age less than 6 month in Bahir Dar city administration, North west Ethiopia. Sci J Clinical Med. 2013;2(6):153-9

15. Hafizan N, Telba Z, Sutan R. Socio-demographic factors associated with duration of exclusive breast feeding practice among mothers in East Malaysia. J Nurs Health Sci. 2014;31(1):52-6.

16. Mekuria G, Endris M. Exclusive breastfeeding and associated factors among mothers in Debre Markos. Northwest Ethiopia Int Breastfeeding J. 2015;10:1.

17. Alemayehu T, Haidar J, Habte D. Determinants of exclusive breastfeeding practices in Ethiopia. Ethiop J Health Dev. 2009;23(1):12-8.
18. Danso J. Examining the practice of exclusive breastfeeding among professional working mothers in kumasi Metropolis of Ghana. Int J Nurs. 2014;1(1):11.

19. Woldie TG, Kassa AW, Edris M. Assessment of exclusive breast feeding practice and associated factors in Mecha District, North West Ethiopia. Sci J Public Health. 2014;2(4):330-6.

20. Saka FJ. Factors influencing exclusive breastfeeding among HIV positive mothers at ilala municipality -Dar es Salaam. Doctoral Dissertation Muhimbili University of Health and Allied Sciences. 2012

21. Taddele M, Abebe L, Fentahun N. Exclusive breastfeeding and maternal employment in Ethiopia. a comparative cross-sectional study. Int J Nutr Food Sci. 2014;3(6):497-503.

22. Lense $\mathrm{G}$, Tefera $\mathrm{B}$, and Fasil T. Factors affecting adherence to exclusive breastfeeding practice in Ambo town and Ambo wereda. Ethiopian Public Health Association; 2009

23. Alemayehu M, Abreha K, Yebyo H, Zemichael K, Gebremichael H. Factors associated with timely initiationand exclusive breast feeding among mothers of Axum town, Northern Ethiopia. Sci J Public Health. 2014:2(5):394-401.

24. Joshi PC, Angdembe MR, Das SK, Ahmed S, Faruque ASG, Ahmed T. Prevalence of exclusive breastfeeding and associated factors among mothers in rural Bangladesh: a cross-sectional study. Int Breastfeeding J. 2014;9:7

25. Muchina EN, Waithaka PM. Relashonship between breastfeeding practice and nutritional status of children aged 0-24 months in Nairobi, Kenya. Afr J Food Agric Nutr Dev. 2010;10(4):1684-5374.

26. Shafei AMHE, Labib JR. Determinants of exclusive breastfeeding and introduction of complementary foods in rural Egyptian communities. Glob J Health Sci. 2014;6(4):236-244.

27. Haroun $H$, Mahfouz M, and Ibrahim B. Breast feeding indicators in Sudan: A case study of Wad Medani town. Sudanese J Public Health: 2008;3(2):81-90.

28. Ajibadde B, Okunlade J, Makinde O, Amoo P, Adeyemo M. Factors influencing the practice of exclusive breast feeding in rural communities of Osun State. Niger European J Bus Manag. 2013;5:15.

29. Nkala TE, Msuya SE. Prevalence and predictors of exclusive breastfeeding among women in Kigoma region. Western Tanzania: a community based crosssectional study Int Breastfeeding J. 2011;6:17.

30. Tan KL. Factors associated with exclusive breastfeeding among infants under six months of age in peninsular. Malaysia Int Breastfeeding J. 2011;6:2.

31. Gijsbers B, Mesters I, Knottnerus JA, Schayck CP. Factors associated with the duration of exclusive breast-feeding in asthmatic families. Oxford University Press. 2008;23(1):158-69.

32. Wuthrich-Reggio, Amyanne. Demographic factors that predict breastfeeding in the early postpartum period in Utah women. All Graduate Theses and Dissertations. 2008, Paper 30. 2008.

33. Pascale KNA, Laure NJ, Enyong OJ. Factors associated with breast feeding as well as the nutritional status of infants (0-12) months: an epidemiological study in Yaounde. Cameroon Pakistan J Nutr. 2007:6(3):259-63.

34. Khanal V, Cruz JLNBd, Karkee R, Lee. AH. Factors associated with exclusive breastfeeding in Timor-leste: findings from Demographic and Health Survey 2009-2010. Nutrients. 2014;6:1691-1700.

35. Sowden M, Marais D, Beukes R. Factors influencing high socio-economic class mothers' decision regarding formula-feeding practices in the Cape Metropole. S Afr J Clin Nutr. 2009;22(1):37-44.

36. Torres A. Peer intervention strategies for breastfeeding promotion among low income Latinas in the US. A Literature Review (Doctoral dissertation, California Polytechnic State University, San Luis Obispo). 2011.

37. Ethiopian Public Health Association. Assessment of Infant and Young Child Feeding Practice In Dabat Town, North West Ethiopia, 2006

38. Amin T, Hablas H, Al Qader AA. Determinants of initiation and exclusivity of breastfeeding in Al Hassa. Saudi Arabia Breastfeeding Med. 2011;6(2):59-68. 